\title{
Development of integrated loose fruit collector machine for oil palm plantations
}

\author{
Mohd Zulfahmi Mohd Yusoff ${ }^{1}$, A. Zamri ${ }^{2}$, M. Z. A. Abd Kadir ${ }^{3}$, W. Z. Wan Hassan ${ }^{4}$, N. Azis ${ }^{5}$ \\ ${ }^{1,2}$ Sime Darby Research Sdn Bhd,Lot 2664, Jln Pulau Carey, 42960 Carey Island, Selangor, Malaysia \\ 3,4,5 Faculty of Engineering, University of Putra Malaysia, 43400, Serdang, Malaysia
}

\section{Article Info \\ Article history: \\ Received Sep 24, 2019 \\ Revised Nov 13, 2019 \\ Accepted Dec 28, 2019}

\section{Keywords:}

Harvesting

Loose fruit

Oil extraction rate

Oil palm

Oil palm loose fruit collection

\begin{abstract}
Oil palm loose fruit have always been part of oil palm harvesting operation. The current manual loose fruit collection by hand picking or raking is contributing to the minimum productivity and large amounts of debris. Effort in future shall be explored for the potential machine or system to collect the loose fruit in the field with the result of clean loose fruit. A new machine for loose fruit collection is being developed and examined which knows as integrated oil palm loose fruit collection machine for collecting loose fruit from the palm base. Consist of three main integrated stages; the suction stage is used to collect the loose fruit, followed by segregating stage, which used to segregate the loose fruit from debris through double layer rotating drum and unloading stage of loose fruit to the 3-4 metric tons bin by using hydraulic tipping cylinder. Result indicates that at least more than $50 \%$ productivity of loose fruit collection were increased. In addition, the clean loose fruit collection resulted with the debris less than $10 \%$. Hence, with this development, better quality loose fruits are collected with minimum debris for further processing in the palm oil mill, which will contribute to better oil extraction rate.
\end{abstract}

This is an open access article under the CC BY-SA license.

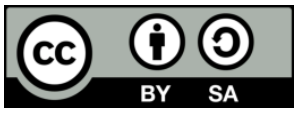

Corresponding Author:

Mohd Zulfahmi Mohd Yusoff, Sime Darby Research Sdn Bhd, Lot 2664, Jln Pulau Carey, 42960 Carey Island, Selangor, Malaysia. Email: zulfahmi.yusoff@ simedarbyplantation.com

\section{INTRODUCTION}

Malaysia is a major global palm oil producer in the world with a planted area of 5.64 million hectares in 2015. The national average yields for the plam oil performance in 2015 are 18.48 tonnes per hectare fresh fruit bunch (FFB), 3.78 tonnes per hectares crude palm oil (CPO), 0.93 tonnes per hectare palm kernel and $20.46 \%$ oil extraction rate (OER). Meanwhile, for the Malaysia gross domestic product (GDP) performance, the oil palm industry contributed approximately RM60-RM70 billion in 2015 and this is expected to increase to RM178 billion by 2020 [1-3]. This performance greatly influenced by the oil palm industry practices.

The oil palm industry practices rely on the harvesting process whereby the loose fruit (LF) collection is main part of harvesting process. The LF collection contributed to the highest amount of oil provided it should not be contaminated by debris and proper managed collected [4-6]. Moreover, as stated by $[7,8]$, the LF contribute the highest of OER with $40 \%$ per weight ratio as compared to FFB with $20 \%$ to $25 \%$ of the OER per weight ratio. In other words, as far as the LF collection is concerned, the more the LF collected, not be contaminated and proper managed, the higher OER can be generated, which result the higher lost income can be save. 
Currently, LF collection are collected manually in the oil palm industries. Throughout the collection process, the worker needs to bring rake, and bags. The workers need to go from palm to palm andsquat down to collect all the scattered LF on the ground by using the rake before put it into the bag. Once the LF bags full, it will be placed at the roadside before being loaded into a tractor. These processes are repeated at every harvested palm tree. The tractor will bring the bags to the sieve which is located at the estate ramp for the cleaning process before they send to the mill, in which consequently will be consumed the time. Studies have shown that [9-11] at least more than $25 \%$ and up to $70 \%$ of the harvester's times have to spend to collect the LFs. Also, it was estimated that the time taken to collect loose fruits was about $30 \%$ of the total fruit handling time and about $28 \%$ of the harvester's time is dedicated to collecting oil palm loose fruits. Its shows that the proportion of time taken to collect oil palm loose fruits in the cutter-carrier team harvesting system was about $43 \%$ for the raking method. In addition, the LF with the manual collection will be consisted with the amount of debris as they need to collect all the scattered LF on the ground by using the rake. As mentioned by $[12,13]$ the debris accumulated in a collected loose fruit can reach up to $60 \%$ of its total weight and this large amount of debris will affect the mill productivity due to debris will absorb the oil content of the fruit.

Hence, the development of the machinery system to collect and manage the LF may contributed to the appropriate way of LF collection [14-16]. There have been a few development of LF collecting machines whereby some of them gave promising productivity that may eventually be used in commercial oil palm plantations. Consists of two main categories of LF collector machine such mechanical loose fruit collector and roller-type oil palm loose fruit picker (RP), both of these categories present the different mechanism development [17-21]. The mechanical loose fruit collector consists of engine, vacuum and compartment whereby this machine is able to pick up all the LF by direct suction method through the vacuum and store the LF inside the compartment. The average output of this machine is up to $1500 \mathrm{~kg} / \mathrm{day} \mathrm{LF}$ collected. On the other hand, for the roller type oil palm loose fruit picker, this machine consists the plurality of wires, rods and an oval-shaped which is able to pick up all the LF on the ground by using roller method and LF will be stored inside the oval shape case.

The average output of this machine is less than $50 \%$ from the mechanical loose fruit collector. Both of these categories machines gave the promising productivity, however, there are still limitation to take into consideration which is contaminated the LF collected. Note that, the contaminated LF collected refer to the debris that contain inside LF collected whereby it shall be carefully separated from the LF before milling. Hence, the development of integrated oil palm loose fruit collector (ILFC) machinery is proposed to overcome the previous machine and manual LF collected whereby there are three mechanism of machine which is suction, segregating the debris and tipping the clean LF collected. Integrated of these mechanism may able to collect, decontaminated debris and manage the LF collected. It is an anticipated that this machine is able to collect the LF, segregate the debris and tipping the clean LF into the bin. For future, there are another mechanism that maybe attached to the ILFC machine as a value added [22-25] such as detection the colour of LF to be collected, monitoring the movement of the ILFC in the field with the intergration of Internet of Things (IoT) and palm oil loader system. This article is focused on the development of ILFC machine whereby the paper is organized as follows; research methods deal with more detailed on the development of ILFC machine and the flow of work in collecting the LF. Then, results and discussion section covered on the performance of ILFC and manual collection method and conclusion section conclude the findings.

\section{RESEARCH METHOD}

A comprehensive explanation regarding the research method being applied is presented. It consists of the flow of research work and the expanding of explanation on the each of research work flow; site visit on the plantation estate, design and development of ILFC and the data collection method. These research work flow is shown in Figure 1. One of the Sime Darby plantation estate was selected as a site visit for a trial-testing machine. It is due to the accessibility, nearest to the Sime Darby Research Centre and the factors of estate environment. Once selected, estate environments were identified which includes the terrain type, land structure and coverage hectares. This estate covers the inland terrain with 436.50 total hectare mature area at average from 141 palms to 178 palms per hectare.

Later, the ILFC machine was designed with the three main mechanism as shown in Figure 2. First mechanism involves with the suction process. The process utilizing the vacuum technique, whereby LF are sucked into air-tight compartment. The air tight compartment will open by itself once the engine throttle is put into idle. From here the LF with debris will flow into the double layer rotating drum by gravity for segregating process. Second mechanism deals with double layers rotating drum to segregate between debris and LF. The LF with debris will be segregated during rotation of double layer drum. Bigger size and longer 
fiber debris such as stone, soil, frond butt and male flower will rotate inside the inner drum and withdrawal towards the end of inner drum into the debris discharge chute. While LF with small size and short fiber debris will drop into the outer layer drum. From there LF and the debris inside the outer layer drum will rotate forward inside the outer layer drum (guided by spiral conveyor). Cleaning process is done during the rotation, whereby small and short fiber debris will drop onto the ground and clean LF will drop into the LF bin (on the prime mover). Movement of loose fruit with debris from inlet to outlet point is guided by a spiral conveyor to increase the efficiency of the machine.

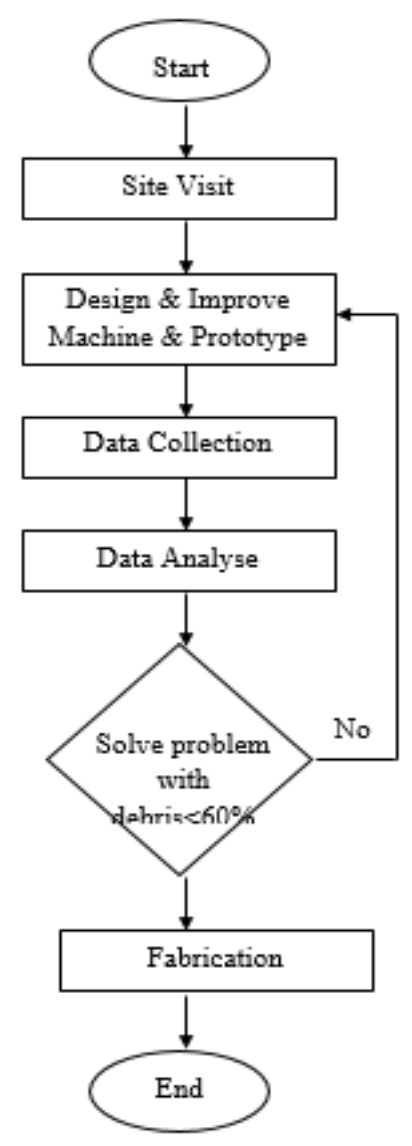

Figure 1. Flow chart of work

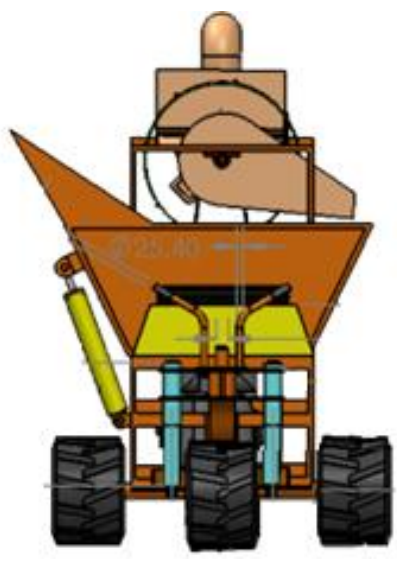

(a)

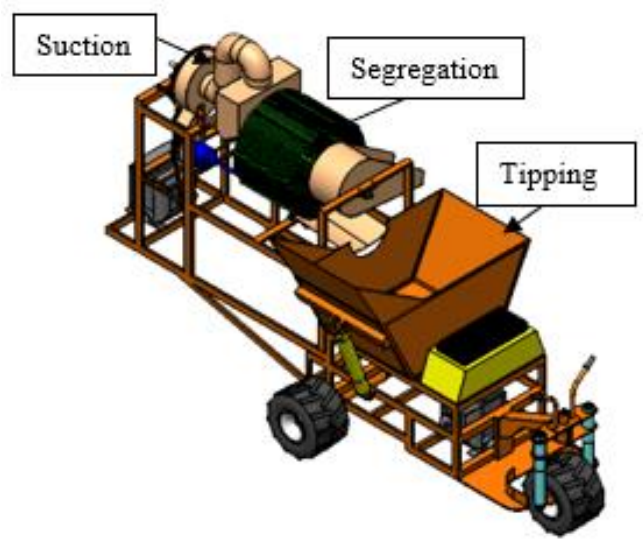

(b)

Figure 2. ILFC configuration view, (a) front, (b) isometric 
Last mechanism covers the three-wheeler attachment whereby the prime mover is equipped with hydraulic tipping bin. When the bin is full, the LF inside the bin is transferred into the 3 tons bin located strategically in the field. The process continue until the 3 tons bin is full. The full 3 tons bin will then hook and lift by tractor and transferred into a haulage tractor or lorry. In short, the machine makes use of direct suction method to collect the LF from the palm base and a double layer rotating drum technique to separate the LF from the debris. Both suction and double layer rotating drum components are attached to 3-Wheeler prime mover. Also, the machine also equipped with hydraulic tipping system to unload collected LF to the 3-4 tons bin. Detailed specifications of ILFC machine are tabulated in Table 1.

Table 1. ILFC machine specification

\begin{tabular}{cc}
\hline ILFC machine & Specifications \\
\hline Length $(\mathrm{m})$ & 3 \\
Height $(\mathrm{m})$ & 2.5 \\
Width $(\mathrm{m})$ & 1.5 \\
Rotating drum speed (rpm) & $20-30$ \\
Fan speed range (rpm) & $4500-5400$ \\
Prime mover engine (hp) & 10 \\
Suction fan and rotating drum engine (hp) & 7 \\
\hline
\end{tabular}

Then, the harvesting data collection was carried out by implementing the ILFC machine over a six month period at Sime Darby plantation estate. Noted that, the ILFC machine was operated by one-man operation machine, whereby the operator machine will drive the ILFC along the harvester path as presented in figure 3. He starts collected all the LF by hold the suction nozzle handle and point the suction nozzle end directly to LF on the ground and start the suction operation. The collected LF will be stored inside the tipping container with the clean LF and then will drive the machine to the 3 tons bin location, once LF is fully loaded and transfer it. The same process repeated for the trial field

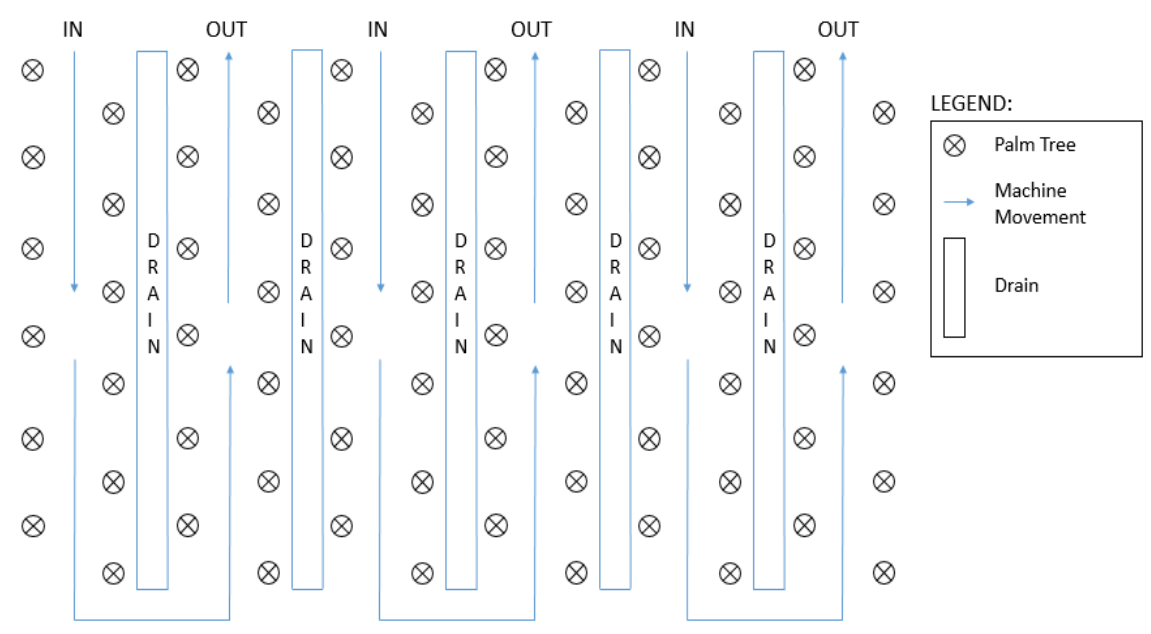

Figure 3. Movement of ILFC machine along harvester path

\section{RESULTS AND DISCUSSION}

In Table 2 shows the comparison results between manual and ILFC machine. Both collection methods are being implemented at Sime Darby plantation estate field trial by following movement trial in Figure 3. The productivity of LF collection for working hour of 8-9 hours per days for both collection methods were measured. Results indicated that at least more than 50\% productivity of ILFC was collected compared to manual collection. Also, this result represents the ability of the machinery to operate for about 8 to 9 hours per day which fits with the harvesting system and compact machine whereby it able to operate with the different soil and topology characteristics in the estate. Hence, the overall of the results shows that the ILFC machine is able to suck the LF, segregate the debris and tipping the clean LF into the bin. Loose fruit collection method shown in Figure 4 (a) and Figure 4 (b). 
Table 2. Comparison of ILFC and manual collection method

\begin{tabular}{ccc}
\hline Description & Productivity (kg/day)* & Debris (\% by weight) \\
\hline ILFC & $650-1000$ & $5-10$ \\
Manual & $150-450$ & $20-30$ \\
Percentage Difference* $(\%)$ & Up to $70 \%$ & Up to $300 \%$ \\
\hline
\end{tabular}

*Productivity $(\mathrm{kg} /$ day $)=$ clean loose fruit

$*$ Percentage Difference $=($ ILFC data- Manual data / (ILFC data + Manual data/2) x 100\%

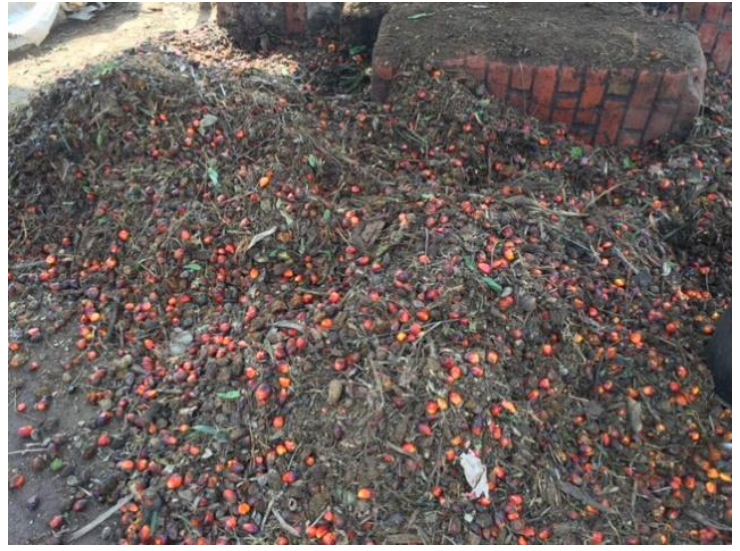

(a)

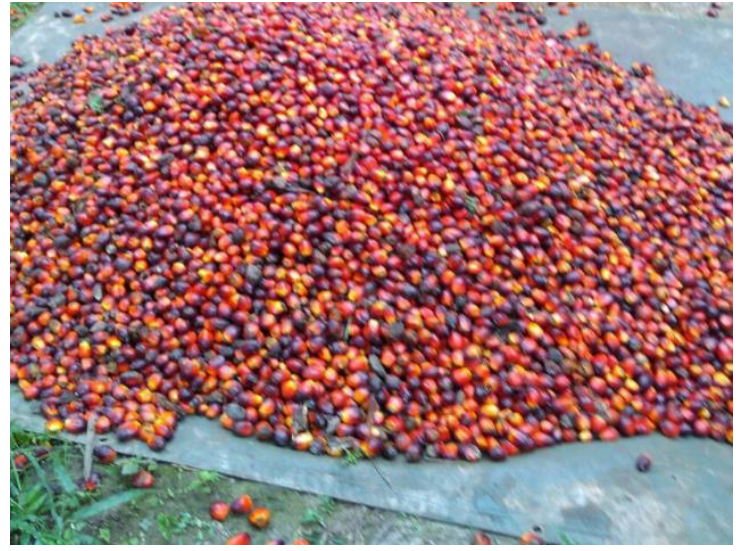

(b)

Figure 4. Loose fruit collection method, (a) manual, (b) ILFC

Lastly, the economic analysis was carried out by assuming: One-man operation to operate the machine. Table 3 shows the economic analysis of ILFC machine whereby the initial cost for the machine is RM35, 000 with the 5-year life span in the field. Based on the estimation of ILFC output at $0.65 \mathrm{mt}$ to $1 \mathrm{mt}$ loose fruit per day, total cost per mt were calculated at RM 73.90 to RM 113 per day.

\begin{tabular}{lc} 
Table 3. The economic analysis of ILFC machine \\
\hline \multicolumn{1}{c}{ Description } & Value \\
\hline Expected machine price & RM35,000.00 \\
Economic life & 5 years \\
Productivity & $0.65-1$ mt/day \\
Machine Depreciation & RM23.30/day \\
Fuel Cost & RM8.30/day \\
Labour cost & RM40.00/day \\
Repair and Maintenance cost & RM2.30/day \\
Total cost & RM73.90 \\
Total cost per mt & RM73.90- RM113 \\
\hline
\end{tabular}

\section{CONCLUSION}

The development of integrated loose fruit collector machine has been discussed. The concept of separation of loose fruit and debris by using the combination of vacuum, double layer rotating drum and tipping is recognized to be effective. The result shows that the machine have a decent performance to carry out the load and works well with the different surface areas. Also, more than $50 \%$ productivity were increase in which provide with the clean loose fruit. Hence, it is anticipated that, the development of integrated loose fruit collector machine possibly will give assistance to the oil palm industries in term of loose fruit collection areas and clean loose fruit before sending to the mill.

\section{ACKNOWLEDGEMENTS}

The authors express their thanks to Sime Darby Research Sdn Bhd and Universiti Putra Malaysia with whose support much of this work was performed under the project entitled "Integrated Oil Palm Loose Fruit Collector". The authors also wish to thanks to Chief Research \& Development Officer of Sime Darby Research Sdn Bhd for permission to publish this paper. 


\section{REFERENCES}

[1] A. Kushairi and A. R. Shuib, "Planter: innovations in oil palm mechanisation," in The Incorporated Society Planters, Selangor, Malaysia, vol. 93, no. 1091, pp. 119-130, 2017.

[2] Malaysia palm oil board oil palm planted area, in Economics and Industry Development Division, 2015.

[3] F. A. Dass, "Plantation industry-the next 100 years: Surging forward," inNational Seminar (NATSEM), Subang Jaya, Selangor, 2017.

[4] N. Fadilah, J.M.Saleh, H.Ibrahim and Z.A.Halim, "Oil palm fresh bunch ripeness classification using artificial Neural Network," in 2012The 4th International Conference on Intelligent and Advanced Systems (ICIAS 2012), no.1, pp. 18-21, 2012.

[5] Z. M. Sharif, N. M. Taib, M. S. Yusof, M. Z. Rahim, A. L. Tobi and M. S. Othman, "Study on handing process and quality degradation of oil palm fresh fruit bunches (FFB)," in IOP Conf. Series Materials Science and Engineering, vol. 203, 2017.

[6] M. R. Khalid and A. R. Shuib, "Oil palm mechanisation: Recent technologies and challenges," in National Conference on Agricultural and Food Mechanisation, Sabah, Malaysia,pp. 404-412, 2014.

[7] D. E. Pebrian and M. Fairulnizam, "Effects of collecting systems and plantation environment in debris accumulation in acollected oil palm loose fruit," in International Conference on Plant Physiology 2014, Indonesia, vol. 2015, pp.147-151, 2014

[8] A. A. Abdul and Y. A. Tan, "The effects of handling of oil palm FFB on the formation of FFA and the subsequent quality of crude palm oil," in In J.Sukaimi (Ed.) Proceedings Palm oil Development Conference, Kuala Lumpur, 1989.

[9] P. D. Turner and R. A. Gillbanks, "Oil palm cultivation and management," in Incorporated Society Planters, Kuala Lumpur, pp. 672, 1974.

[10] L. T. Gan, C. Y. Ho., J. S. Chew, K. S. Lam and T. T. Kee, "Recent developments in harvesting practices to maximize labour productivity, oil yields and profits," in Proc Int. Planters Conf. Management for enhanced profitability in plantation (Ed. By K.H. Chee), Incorporated Society of Planters, Kuala Lumpur, pp. 315-336, 1994.

[11] B. H. Webb, "The development of suitable infield FFB harvesting systems to improve the efficiency of oil palm production," inInt. Development in Oil Palm, Incorporated Society of Planters, 1977.

[12] L. T. Gan, C. Y. Ho, K. S. Lam, and J. S. Chew, "Optimum harvesting standards to maximise labour productivity and oil recovery,'.in Proc. Int. Palm Oil Congress Agriculture, Palm Oil Research Institute of Malaysia, Kuala Lumpur, pp. 195-221, 1995.

[13] A. Hitam., A. Z. Mohd.Yusof and M. S. Jaffar, "Loose fruit collector," in Palm Oil Research Institute of Malaysia (PORIM), Selangor, no. 19, 1995.

[14] B. Bek-Nielsen, "Quality aspects of oil palm kernel production," inThe quality and marketing of palm oil products (Ed. By P.D.Turner), Incorporated society of planters, Kuala Lumpur, pp. 161, 1969.

[15] J. De Souza, "Basics of an integrated evacuation system," in Planter, pp. 235-239, 2003

[16] C. F. Lai, "Mechanical fertiliser spreaders for oil palm conditions-types and costs with emphasis on the turbo-spin air assisted fertiliser spreader," in Planter, vol. 76, no. 893, pp. 483-492, 2000

[17] A. Z. Mohd.Yusof and A. Hitam, "Mechanical loose fruit collector," in Information Series No.57, Palm Oil Research Institute of Malaysia (PORIM), Selangor, 1999.

[18] A. R. Shuib, M. R. Khalid, M. S. Deraman and A. Mohamed, "Oil palm loose fruit collector," Palm Oil Research Institute of Malaysia (PORIM), no.505, Selangor, 2012

[19] A. R Shuib., M. R. Khalid, M. A. Bakri, A. Mohamed and N. Salleh, "Oil palm loose fruit collecting machine with elevated discharge mechanism," in Palm Oil Research Institute of Malaysia (PORIM), Selagor, no.751, 2017.

[20] A. Z. Mohd. Yusof and Mohd. Z. Mohd Yusoff, "A motorized device for picking and collecting loose fruit," in WO 2016/072829 AI, 2016

[21] S. Deraman., A. R. Shuib, and M. S. Jaafar, "Roller-type oil palm loose fruit picker," in MPOB Information Series, ISSN 1511-7871, 2009.

[22] Mujiarto, A. Djohar, M. Komaro, M. A. Mohamed, D. S. Rahayu, W. S. M. Sanjaya, M. Mamat, A. Sambas and Subiyanto, "Colored object detection using 5 Dof robot arm based adaptive Neuro-Fuzzy method," in Indonesian Journal of Electrical Engineering and Computer Science, vol. 13, no. 1, pp. 293-299, 2019.

[23] M. S. M. Alfatni, R. M. Shariff, H.Z.M.Shafri,O.M.B.Saed, and O. M. Eshanta, "Oil palm fruit bunch grading system using red, green and blue digital number," in Journal of Applied Sciences, vol. 8, pp. 1444-1452,2008.

[24] M. A. F. Ismail, M. N. Md. Isa, S. N. Mohyar, M. I. Ahmad, M. N. M. Ismail, R. C. Ismail, A. Harun and S.A.Z Murad, "e-PADI: An IoT-based paddy productivity monitoring and advisory system," in Indonesian Journal of Electrical Engineering and Computer Science, vol. 14, no. 2, pp. 852-858, 2019.

[25] S. Sarip, M. A. Suhot, H. M. Kaidi, M. F. Mohd Noor, S. Abdul Aziz, N. A. Bani and M.S Noorazizi, "Hydraulically operated palm oil loader system design as fresh fruit bunch collector," in Indonesian Journal of Electrical Engineering and Computer Science, vol. 17, no. 1, pp. 228-236, 2020. 


\section{BIOGRAPHIES OF AUTHORS}
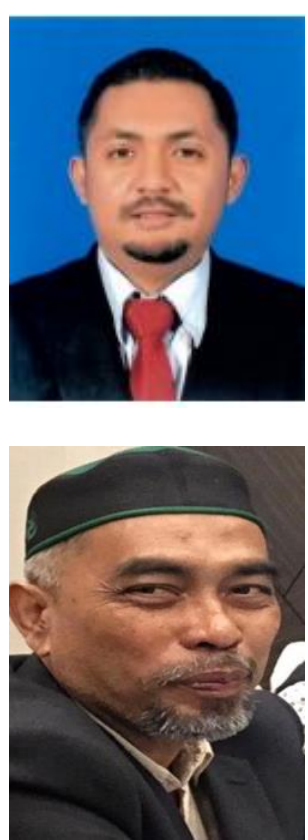

Ahmad Zamri Md Yusof was graduated from Universiti Putra Malaysia (UPM) with Bachelor of Engineering (agriculture) degree in 1994. He is dedicated to his work to deliver results and has 11.7 years in current position as Head, Mechanisation Unit, R\&D. Very strong technical and competency in field mechanisation with main focus on FFB and loose fruit collection and cleaning. That includes the development of motorised wheelbarrow, loose fruit segregator and collector, mechanical buffalo with scissor lift, mechanical buffalo grabber etc. To date, he has filed 10 patents/IP related to in field FFB and LF mechanization and published and presented 32 papers in various conferences.

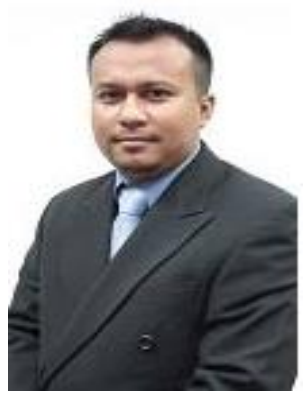

Prof. Ir. Dr. Mohd Zainal Abidin Ab Kadir is a Professor at CELP UPM and with the Faculty of Engineering, UPM. Currently, he is seconded as Strategic Hire Professor at Universiti Tenaga Nasional (The National Energy University) Malaysia. He is a WG Member of IEEE PES Lightning Performance on Overhead Lines and the Advisor of CELP, UPM. He is an Advisory Board Member for National Lightning Safety Institute (NLSI), USA and Local Convener of SC C4 of MNC-CIGRE. He is a Professional Engineer and a Chartered Engineer, as well as member of IEM, IEEE, IET, CIGRE. Prof Zainal is also an IEEE PES Distinguished Lecturer.

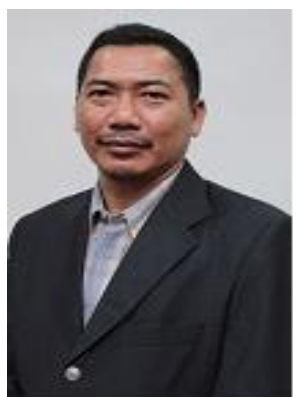

Assoc. Prof. Dr. Wan Zuha Wan Hasan received the degree in Electrical and Electronic Engineering from Universiti Putra Malaysia in 1997. He received the Ph.D. degree in Microelectronic Engineering from the Universiti Kebangsaan Malaysia in 2010. Currently, he is an associate professor at Department of Electrical and Electronic Engineering, Universiti Putra Malaysia and Deputy Dean (Undergraduate Studies), Faculty of Engineering, Universiti Putra Malaysia. He was a postdoctoral research fellow at University of Southampton from December 2011 to November 2012. He is an active leader of Robotic UPM for robotic innovations and competitions. He is a Technical Editor for various International Journals as well as a reviewer of various submitted journal and conference proceeding publication.

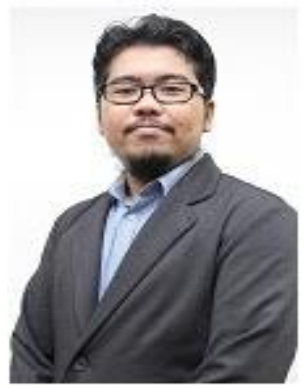

Assoc. Prof. Dr. Norhafiz bin Azis received the degree in Electrical Engineering from Universiti Putra Malaysia in 2007. He received the Ph.D. degree in Electrical and Electronic Engineering in 2012, from the University of Manchester. Currently, he is an associate professor at Department of Electrical and Electronic Engineering, Universiti Putra Malaysia. 